\title{
The Role of Universities and Entrepreneurial Ecosystem in Producing Entrepreneurs for Industry 4.0
}

\author{
Altaf Hussain Samo \\ Sukkur IBA University \\ Nisar Ahmed Channa \\ Sukkur IBA University \\ Naveed Akhtar Qureshi \\ Sukkur IBA University
}

\begin{abstract}
Entrepreneurship is regarded as a tool to boost economic growth and alleviate poverty. A number of individuals from both developing and developed countries engage in entrepreneurial activities every year, but their success ratio is very low. In addition to that, recently scholars show concerns regarding the effectiveness of degree programs specialized in entrepreneurship being offered at universities in producing entrepreneurs for industry 4.0. This research aims to address these concerns studying the entrepreneurial intentions of students and the role played by Pakistani universities in producing entrepreneurs. To this end, we adopted data triangulation method by incorporating a case study method followed by semi-structured interviews. The results suggest that environmental factors significantly contribute to entrepreneurial intentions. Similarly, we found an underrepresentation of entrepreneurial courses at various degree programs in Pakistani universities. The findings further suggested that although relevant infrastructure and other facilities required by an effective entrepreneurial ecosystem are present in Pakistani universities, there is need of synchronization between the universities and elements of entrepreneurial ecosystem.
\end{abstract}

Keywords: entrepreneurial intentions, fourth industrial revolution, university graduates, Pakistani universities, entrepreneurial eco-system, case study

\section{INTRODUCTION}

Entrepreneurship is regarded globally as a vital source of economic growth and a prominent factor influencing socio-economic well-being of society. Scholars considered entrepreneurship as an essential source of job creation, poverty alleviation, innovation, societal development, and economic competitiveness. A number of individuals including university graduates engage in entrepreneurial activities either by starting their own venture or joining their existing family business, but their success ratio is very low. According to Matos \& Hall (2020), majority of entrepreneurs in developing countries failed because of unavailability of institutional mechanisms and personal characteristics of entrepreneurs. According to Global Innovation Index (2019), Pakistan ranks 105 in global innovation index. Similarly, 
Global Creativity Index and Global Technology Index suggests that Pakistan ranks 0.053 and 73 in creativity and technology respectively. These rankings shows lack of innovation, creativity, and technological advancement in the country. Following Baumol (1990), Matos and Hall (2020) suggest that innovation is correlated with productive entrepreneurship. Additionally, the unavailability of institutional mechanisms and formal or informal education hinder innovation and implicitly encourage subsistence business activities (Bruton et al., 2015; Viswanathan et al., 2014).

Entrepreneurship education is used as a tool to enhance entrepreneurial activity (Bischoff, Volkmann, \& Audretsch, 2018). Petkovic and Kisic (2019) postulated that by introducing entrepreneurship as an educational discipline at all formal and informal educational levels can make a significant contribution to economic growth and socio-economic development of emerging economies, by strengthening entrepreneurial ecosystem of educational institutions at all levels. In developed economies, entrepreneurship education at all educational levels is considered as an essential part of the entrepreneurial ecosystem. A number of universities offer various degree programs at both graduate and postgraduate levels to impart the specific knowledge necessary for the effective creation and successful continuation of entrepreneurial ventures. Recently, various scholars around the globe show concerns about whether these degree programs being offered at universities worldwide are capable to produce graduates for fourth industrial revolution (Teng et al., 2019). It is because the modern era of automation does not only require the development of digital skills, but also requires emotional and social skills (Petkovic \& Kisic, 2019). Academic research suggests that traditional employment skills focused on production of goods are not relevant in era of fourth industrial revolution. In order to meet the future job requirements, there is need to develop skills of innovation, creativity, critical and analytical thinking, negotiation and decision making, and communication skills. At the same time, there is a debate about whether degree programs in entrepreneurship can enhance strengths, and overcome the limitations associated with individual characteristics (such as openness) and personal circumstances (such as family background) (Liñán, 2004). This debate becomes more complicated when considering the economic and business context in which an individual might practice entrepreneurship. Academic research also suggests that entrepreneurial attitudes, intentions and behaviors develop and change over time (Lee \& Wong, 2004). The research conducted by Lee and Wong (2004) offers a lifecycle view of entrepreneurial development. The lifecycle view suggests that the decision to start business might be affected by the entrepreneurs' personal experiences over time including their formal educational experiences along with their experiences of the opportunities for and barriers to entrepreneurship afforded by their environment. In turn, these experiences are likely to influence the beliefs and attitudes that affect entrepreneurial intentions and, when circumstances permit, entrepreneurial behavior.

The objectives of this study are three fold: 1- to study the environmental factors (i.e. education, family, and society) affecting students' career choice to become an entrepreneur; 2- to study the role of universities in producing entrepreneurs for fourth industrial revolution; 3- to study the entrepreneurial eco-system of universities.

\section{RESEARCH QUESTIONS}

RQ1: Does environmental factors shape entrepreneurial intentions?

RQ2: Do Pakistani universities are playing their role in producing entrepreneurs for fourth industrial revolution?

RQ3: Does the entrepreneurial eco-system of Pakistani universities shape students' intention to start technological startups? 


\section{LITERATURE REVIEW}

\section{Environmental Factors and Students' Intention to Become an Entrepreneur}

Academic research suggests that family plays a key role in shaping students' intention to become an entrepreneur (Carr \& Sequeira, 2007). Study conducted by Shapero and Sokol (1982) suggested that the mother and father play prominent roles to determine the feasibility and desirability of the venture. Parents serve as the role model for their children and children depict acts of their parents, therefore there is possibility that if the parents of a child are entrepreneurs, the child would also have a strong preference to become an entrepreneur (Manimala et al., 2006; Mohd Dali et al., 2014; N. Krueger et al, 2000; Zhao et al., 2010). Drennan et al. (2004) categorized family background into three categories: 1- prior exposure to family business; 2- a difficult childhood; and 3- frequent relocation as a child, and concluded that exposure to entrepreneurship in early age and experience of family business impacts family members' attitudes and intentions towards entrepreneurship. In addition to that, researchers have extended family background to include genetic dispositions (Laspita et al., 2012; Nicolaou \& Shane, 2010). These studies suggested that entrepreneurial background of parents and grandparents generates communication and structural patterns that promotes strong preference for entrepreneurship in the grandchildren.

Noting the importance of entrepreneurship, academics are putting their efforts to promote entrepreneurial mindset in educational institutes. Academic research has confirmed that education is a key component in creation and development of entrepreneurial attitudes (Kourilsky \& Walstad, 1998; Gorman et al., 1997). Formal education helps individuals to identify their entrepreneurial interest and learn ways to formulate and execute their strategic plan (Turker \& Selcuk, 2009). In addition to gain required knowledge to run a business, education helps entrepreneurs to achieve business performance in turbulent and competitive business environment (Gelaidan \& Abdullateef, 2017). In literature, educational support is defined as "a set of initiatives designed to improve national economic development through constant investment in quality education bolstered by an adequate number of teachers and relevant learning tools" (Gelaidan \& Abdullateef, 2017, p. 56). In given definition, it is clearly understood that education and education significantly contributes to human resource development, thus a strong link between education and entrepreneurship can be emphasized (Galloway \& Brown, 2002; Henderson \& Robertson, 2000).

According to De Carolis and Saparito (2006), social cognitive theory suggests that social environment in which an individual is surrounded plays a decisive role in developing their cognition and behavior. Santos et al. (2016) postulated that social status of entrepreneurship as a respected career path significantly contributes to enhance individuals' interest in entrepreneurship. The cognitive perspective of social capital plays a unique and complementary role in transmission of ideas and values that influence intentions and perceptions (De Carolis \& Saparito 2006). Similarly, study of Fayolle et al. (2010) highlighted the importance of the interplay between different levels of social influence while explaining entrepreneurial orientation. Social influence plays a role in shaping entrepreneurial behaviors and attitudes at both micro and macro levels (Morris \& Schindehutte, 2005). The micro level of social influence comprised of the links with family, relatives, friends, and acquaintances (Uphoff, 2000). Whereas, the macro level of social influence is made up of shared social values and culture of the society (Thornton et al., 2011).

\section{The Role of Universities and Entrepreneurial Ecosystem in Producing Entrepreneurs for Industry 4.0}

Noting the importance of entrepreneurship education, academics around the globe emphasizing the need to adapt entrepreneurship education and training systems to prepare graduates for knowledge based economy (Klofsten et al., 2019). Entrepreneurship education contributes to technological and social transformations and helps students to develop knowledge, skills and competencies in today's competitive innovation and technology driven economy (Qureshi \& Mian, 2020). Recently the investigation of entrepreneurship study contexts and dimensions, programs axiology, ontology, pedagogy, support mechanisms, and teaching models that impact entrepreneurial opportunity identification and venture development have become point of interest for researchers (Fayolle \& Gailly, 2008). 
Contrary to prior three revolution, fourth industrial revolution or industry 4.0 is characterized by the parallel development of a swath of seemingly independent technologies having potential to change the world. These technological advances promise huge benefits to society. However, the fourth industrial revolution also poses serious challenges in terms of realignment of labor markets and supply chains, skills shortage and disruptive business models (Ramakrishna et al., 2020). The role of universities in shaping technology advancements is very critical because universities serve as test beds for innovation to educate future generations (Ramakrishna et al., 2020). Although, the traditional education significantly contributed to present levels of technological advancements, however, to deliver right set of knowledge, skills and competencies to future generations in order to effectively contribute to fourth industrial revolution, the delivery of education should transform to combine the strength of the traditional higher education with digital innovations (Ramakrishna et al., 2020).

In recent times, universities have significantly contributed to promoting entrepreneurship and innovation in their regions (Klofsten et al., 2019). Universities provide entrepreneurship education and develop entrepreneurial mindset, equip students with different entrepreneurial skills, and enable them to expand their social network (Fayolle \& Gailly, 2008). Universities often collaborate with other stakeholders to ensure and enable entrepreneurial ecosystem (Mason \& Brown, 2013). Academic research suggests that sustainable entrepreneurial ecosystem should connect people having ideas with partners, and resources to connect the dots in bridging assets. This bridging of facilities and assets in knowledge creation (Nonaka, 1994) and knowledge transfer lays the foundation of an entrepreneurial society, which in turn becomes a key driver of economic growth (Audretsch, 2009).

\section{METHODOLOGY}

To answer the research questions, this study adopts methodological triangulation approach. According to Sands and Roer-Strier (2006), methodological triangulation uses a variety of data collection methods such as interviews, focus group, participant observation, survey, and it can also encompass a combination of both qualitative and quantitative methods. Initially, a case study approach was adopted and as a followup, semi-structured interviews were conducted from faculty members and managers of incubation centers of three public sector universities in Pakistan.

\section{Case Study}

Although, academic literature offer interesting insights regarding the factors that shape entrepreneurial intentions among students, still there are some unanswered questions as whether the curriculum being taught in universities prepares graduates to meet the requirements of today's highly competitive global environment, whether the current curriculum being taught in universities helps students to develop technical and analytical skills required to exploit the entrepreneurial opportunities. These questions provided motivation to conduct this study that is from empirical perspective.

A case study research method was adopted to analyze the level of development of the entrepreneurial ecosystem in three leading public universities in Pakistan. According to Gerring (2004, p.341), case study is "an in-depth study of a single unit (a relatively bounded phenomenon) where the scholar's aim is to elucidate features of a larger class of similar phenomena". The unit of analysis of study 1 is the business schools selected universities (Miller \& Acs, 2017). We used following methods to collect data:

1. Analysis of different degree programs being offered at universities (i.e. whether entrepreneurship courses being offered are compulsory or elective, how many credit hours each course contains).

2. Analysis of existence and functioning of incubation centers and entrepreneurship development centers. 


\section{Interviews}

Sampling

Purposive sampling technique is employed to collect data by using semi-structured interviewing technique from 3 full-time senior faculty members teaching entrepreneurship courses and supervising students of master and $\mathrm{PhD}$ programs and 3 incubation center managers at three different universities of Pakistan. Bryman and Bell (2015) regarded purposive sampling as a form of non-probability sampling. In purposive sampling, researcher can "sample cases/participants in a strategic way, so that those sampled are relevant to the research questions being posed" (Bryman and Bell, 2015, p.442). We choose this sample because objective of this study is to study the entrepreneurial intentions of the students and the role of universities in producing entrepreneurs for fourth industrial revolution, hence we believe that the teachers and incubation center managers are the best source get information about the students' entrepreneurial intentions and universities' role in producing entrepreneurs.

\section{Data Collection}

According to Cohen and Crabtree (2006) by giving a set of clear instructions, semi-structured interviews provide comparable and reliable qualitative data. We conducted semi-structured interviews in a very pleasant environment inside university premises. An interview guideline comprised of ground rules, ethical consideration and semi- structured interview questions was developed. The interview questions were developed on basis of research objectives and literature review. The interview questions were classified into three categories:

1. Throw away questions

2. Essential questions

3. Concluding questions

\section{Data Analysis}

The framework analysis techniques was used to analyze the data. First, from interview recordings were transcribed in to the interview transcripts. Second, the researchers thoroughly read memos and interview transcripts. Third, initial codes were assigned on the basis of priori and initial issues. Fourth, after assigning initial codes, specific textual codes were assigned to different pieces of data related to different themes. Finally, first, second and third order coding was done and we generated three main themes on basis of which we draw results and conclusions.

\section{RESULTS}

\section{Case Study}

\section{University 1}

Although, despite of the fact that details regarding some subjects included in curriculum were not available, still we covered the majority of study programs and courses available for enrollment in academic year 2019-2020. Generally, a trend of increasing entrepreneurship subjects in curriculum of degree programs was noticed. We found that in course schemas of previous academic years (i.e. 2018-19, 201718, 2016-17) the number of entrepreneurship courses were less than the entrepreneurship courses in course schemas of academic year 2019-2020. In addition to this, we also found that in previous academic years, there were no entrepreneurship courses in course schemas of degree programs offered in department of engineering, however, we noticed that in academic year 2019-2020, there were entrepreneurship courses included in course schemas of different degree programs offered in department of engineering. Statistics further revealed that the course content of different entrepreneurship courses currently being taught at different degree programs management oriented rather than related to entrepreneurship. It was also noted that these entrepreneurial subjects mainly offered in third or fourth year of undergraduate degree program and these were core credit subjects mandatory for students to pass to meet requirements of their degree program. Each subject comprised of 3.0 credit hours. 
In addition, we consider the provision of practical experience and exposure to professional business practice as an indicator of how students are supported to gain real time practical experience, skills, knowledge and abilities before graduation. We found that a fully functional business simulation lab equipped with all latest technologically advanced equipment is situated at the campus where the students of the department of business administration are simulated with real time business problems and they are asked to solve those problems by using their analytical and problem solving skills. Similarly, a six months corporate internship is mandatory for the students of business department to get their final degree.

\section{University 2}

We covered all degree programs of university 2, available for enrollment in academic year 2019-2020. Generally, a trend of promoting entrepreneurship across the various academic disciplines was observed while studying the course schemas of different degree programs currently being offered at various faculties and departments of university 2. Interestingly, we found that since last five years, entrepreneurship subject are being taught to almost every undergraduate degree program including in faculties of engineering and technology. It suggest the vision and determination of university management to produce entrepreneurs for every sect of society instead of just focusing to one particular discipline (i.e. business, management). We also found that university 2 business school is offering a specialized master degree program in Innovation and Entrepreneurship. Master of Science in Innovation and Entrepreneurship students are being taught 10 different subjects of innovation and entrepreneurship and students are required to complete a compulsory thesis as partial requirement of the degree program. It was further observed that in flagship degree programs of university 2 business school (i.e. BBA \& MBA), only one compulsory entrepreneurship module is being taught, it suggests that these programs are management oriented rather than developing entrepreneurial intentions among students. It was also noted that entrepreneurial subjects mainly offered in degree programs were core credit subjects mandatory for students to pass to meet requirements of their degree program. Normally each subject comprised of 3.0 credit hours.

Like in case of University 1, we consider the provision of practical experience and exposure to professional business practice as an indicator of how students are supported to gain real time practical experience, skills, knowledge and abilities before graduation. We found that a fully functional business incubation center equipped with all facilities is working at the university 2 , which is beneficial for the students intend to start their venture upon or even during their studies. Likewise, a six months corporate internship is a degree requirement for the students of university 2 business school.

\section{University 3}

Generally, we observed that entrepreneurship courses are only being taught at four degree programs of business school and one degree program of school of social sciences and humanities. We do not found any entrepreneurship subject in course schemas available on websites of other degree programs currently being offered at other faculties. The total number of entrepreneurship courses being taught at different degree programs of university 3 is only 5 , which suggest that the number of entrepreneurship courses at university 3 is underrepresented.

We also noticed that out of these five degree programs where entrepreneurship courses are being offered, three were master and two were bachelor. Out of five, there were only two master degree programs where the entrepreneurship courses are being taught as core subjects, in remaining three degree programs, entrepreneurship courses are being offered as electives. These facts suggest that the degree programs offered at university 3 are designed to provide theoretical knowledge of relevant discipline to graduates, not to develop entrepreneurial intentions among graduates to start their own business venture.

Similarly, like previous cases of university 1 and university 2, the provision of practical experience and exposure to professional business practice was considered as an indicator of how students are supported to gain real time practical experience, skills, knowledge and abilities before graduation. We found that a fully functional state of the art business incubation center equipped with all latest technologically advanced equipment is situated at the campus to facilitate the students starting their business ventures. A state of the art FAB Lab was is also situated at the campus to facilitate the students of engineering school to further 
enhance their technical skills. Similarly, a six months corporate internship is a mandatory degree requirement for the students of business school.

\section{DISCUSSION}

The findings of study 2 reveals that most of the curriculum currently being taught at Pakistani universities is up-to date, however the number of entrepreneurship courses currently being taught at universities is very limited. Particularly, the number of entrepreneurship courses in various degree programs being offered in discipline of business management is surprisingly very limited. In four years bachelor degree program, only one entrepreneurship course is being offered in all universities included in sample of this study. The case become even worst in business management master degree programs being offered in these universities where only one university offers entrepreneurship courses in their master degree programs. Initially we assumed that these universities do not offer entrepreneurship courses because they only offer admission to those candidates who have completed their bachelor degrees in business management disciplines and already studied entrepreneurship courses in their undergraduate degree program, but after looking at their admission criteria to those degree programs, we came to realize that the admission to these programs is not restricted to only business graduates rather, graduates from any discipline can apply for admission. This finding is very surprising and alarming that business schools do not offer any entrepreneurship course in their flagship degree programs like Master of Business Administration (MBA).

Studying entrepreneurial eco-system of universities, we came to know that all universities included in our sample have an entrepreneurial eco-system that can compete with any best university of the world. All universities have sate of the art incubation centers equipped with modern equipment and consultation services are being offered to young entrepreneurs. In addition to that, various universities have facilities like IT parks, where university support students having business idea related with information technology by providing them couching and mentorship. It is a positive sign that Pakistani universities have noted the importance of information technology in upcoming fourth industrial revolution and hence, preparing their students to start IT ventures. We also found that universities have other world class facilities like FAB labs, trade labs, and business simulation labs where students get chance to solve in real world business problems by using their conceptual and analytical skills.

Finally, we conclude that the reason behind underrepresentation of entrepreneurship subjects in various degree programs being offered at Pakistani universities is due to the fact that entrepreneurship is considered as establishing and managing small medium enterprises, contrary to that, in actual the concept of entrepreneurship is far beyond this conceptualization. First, entrepreneurship stresses proactivity, innovativeness and risk-taking. In given assertion, the inclusion of entrepreneurship courses in curriculum should be considered as a way to promote critical thinking and innovativeness, which is much more than teaching management of small medium enterprises to students. Although, the curriculum is not the only element of university entrepreneurial ecosystem, but it is regarded as first step towards its establishment as it directly impacts the performance of students.

\section{INTERVIEWS}

To further strengthen the findings of current study, we conducted semi-structured interviews with managers of university incubation centers and fulltime faculty members who are currently teaching entrepreneurship courses in different universities of Pakistan.

\section{The Role of Environmental Factors in Shaping Students' Entrepreneurial Intentions}

Our findings revealed that all of the respondents seem to agree with the fact that environment plays a key role in shaping students' intention to start their business venture. Most importantly, the role of family background is very important in influencing the intention of students to a business. Particularly the role 
played by father and mother in determining the desirability and feasibility of the venture is very decisive. In this regard, one of the respondent added that:

"In collectivist societies like Pakistan, if a child has a business idea, his/her mother or father will be the first to whom he/she will discuss the feasibility and financial prospects. It is because the mother or father who make financial decisions in family will be the ultimate source of funding, hence their desirability will ultimately decide the fate of business venture".

Another interesting factor we came to know in determining intention to start the business is the entrepreneurial background of the family. Respondents also seem unanimously agree to the fact that there are relatively more chances of starting business venture among students whose father or mother is also an entrepreneur. It is because children consider their parents as role models and mimic actions and behaviors of parents in their everyday life, therefore there are chances that children will mimic entrepreneurial behavior of their parents by starting their venture. In this regard one of the respondent stated:

"In our society, there is trend of adopting the profession of parents, particularly the profession of father and grandfather. The child of a doctor wanted to be a doctor, the child of an engineer wanted to be an engineer, and the child of a teacher wanted to be a teacher. Similarly there are chances that the child of an entrepreneur also wanted to be an entrepreneur".

Our findings also suggest that students identify their entrepreneurial intentions while still in school. Students who identify their entrepreneurial intentions take entrepreneurship courses during their formal university education which further help them to transform their business idea into business venture. Formal entrepreneurship education at university level help students to understand the ways in which the business strategic plans can be developed and executed. A respondent shared his views in this regard:

"Although entrepreneurship is nothing to do with formal education. You can see a number of successful entrepreneurs around who don't have any formal education or university degree but still they are successful. But the thing that differentiate an entrepreneur having formal educational background and an entrepreneur without having formal education is the fact that an educated entrepreneur move in a strategic direction and he knows how to transform a problem into opportunity".

\section{The Role of Universities and University Entrepreneurial Ecosystem in Producing Entrepreneurs for Fourth Industrial Revolution}

The findings of this research endeavor suggest that educational institute and university entrepreneurial ecosystem are among the key factors that shape students' entrepreneurial intentions. Our findings further revealed that entrepreneurship courses and specialized degree programs currently being offered at Pakistani universities significantly influence students' entrepreneurial behavior. For instance, almost every Pakistani university no matter whether its public sector or private sector have included different entrepreneurial courses in their course schema as mandatory subjects, which means in order to meet degree requirements, it is mandatory for students to take entrepreneurial subjects. Our findings reveal that majority of students who enroll in an entrepreneurship course during their formal education have business ideas and consider to start their business upon their graduation, as entrepreneurship education enhances individual awareness regarding entrepreneurship as an alternative career path. One on the respondent added that:

"Our university like many others in Pakistan have at least one mandatory entrepreneurship course in a four year bachelor degree program in each faculty. These entrepreneurship courses are significantly contributing to influence students' entrepreneurial behaviors and 
provoke a sense of creative thinking among students in order to convert challenges into business opportunities".

There were some participants who did not agree with the view that degree programs currently being offered in business schools like bachelor of business administration and master of business administration are effective in producing entrepreneurs. The respondents who supported this view emphasized the need to design and start new specialized degree programs in entrepreneurship in order to develop entrepreneurs who can contribute to social development and economic growth of the country. One of the responded stated that:

"Entrepreneurship and business management are two different things. Our business programs are designed with the aim to develop business management skills among graduates that help them to manage operations of the business. On the other hand, entrepreneurship education is mainly concerned with developing skills, intentions, and attitudes related with venture creation. Therefore, I am not agree with the view that these degree programs in business schools are effective in developing entrepreneurs".

However, despite the effectiveness of these entrepreneurship courses, our findings also revealed the underrepresentation of the number of entrepreneurship courses currently being offered at various universities. For instance, in a four year degree program, students have to take 48 courses, out of these 48 the number of courses related with entrepreneurship is only one. Even the flagship programs of various business schools like master of business administration, there is not a single entrepreneurship course being offered. Apart from this underrepresentation in business degrees, we found that degree programs being offered at other faculties like engineering, computer science, social science also included entrepreneurship courses in their schemas as mandatory course. A number of respondents seem agree to the fact that due to these entrepreneurship courses, a surge increase in business startups related with information and technology (IT) has been seen, which shows the effectiveness of these degree programs and entrepreneurship courses in producing entrepreneurs for fourth industrial revolution.

When we discussed with participants regarding universities' entrepreneurial ecosystem, it was revealed that entrepreneurial ecosystem of Pakistani universities comprised of several elements like business school, trade labs, business simulation lab, office of research innovation and commercialization, business incubation center, commercial and investment banks, chamber of commerce, local industry, small medium enterprise development authority, district government, and special economic zones (please refer Figure 1). All participants unanimously suggested that although entrepreneurial ecosystems of Pakistani universities are effectively working, still there is need for improvement to sync all elements exist in an entrepreneurial ecosystems. As one of the participant responded:

"Entrepreneurial ecosystem in our university is effectively working, however there is need to improve synchronization among elements in entrepreneurial ecosystem. It seems that all elements in ecosystem are not well connected with each other, thus they are not producing ideally desired outputs. For instance, there is a huge gap between the industry and the local industry. University is unaware what kind of skills are required by local industry from university graduates, resultantly the graduates being produced by universities do not possess skills required by the industry".

In similar way, another respondent said:

"Over the last few years, I saw a huge gap between industry and academia and I can conclude that both of these are not synced with each other in an effective manner. The research currently being conducted and published is not aligned with the needs and requirements of local industry sectors". 
Therefore it can be inferred from these findings that although relevant infrastructure and other facilities required by an effective entrepreneurial ecosystem are present in selected Pakistani universities, this ecosystem is unable to produce desired results because these are not connected with each other. Hence, there is need of synchronization between the elements of entrepreneurial ecosystem. Specially, there is need to enhance cooperation between industry and academia. The effective synchronization between industry and academia will enable universities to provide relevant knowledge and develop skills among students that are required by industry and future jobs.

\section{FIGURE 1
UNIVERSITY ENTREPRENEURIAL ECOSYSTEM}

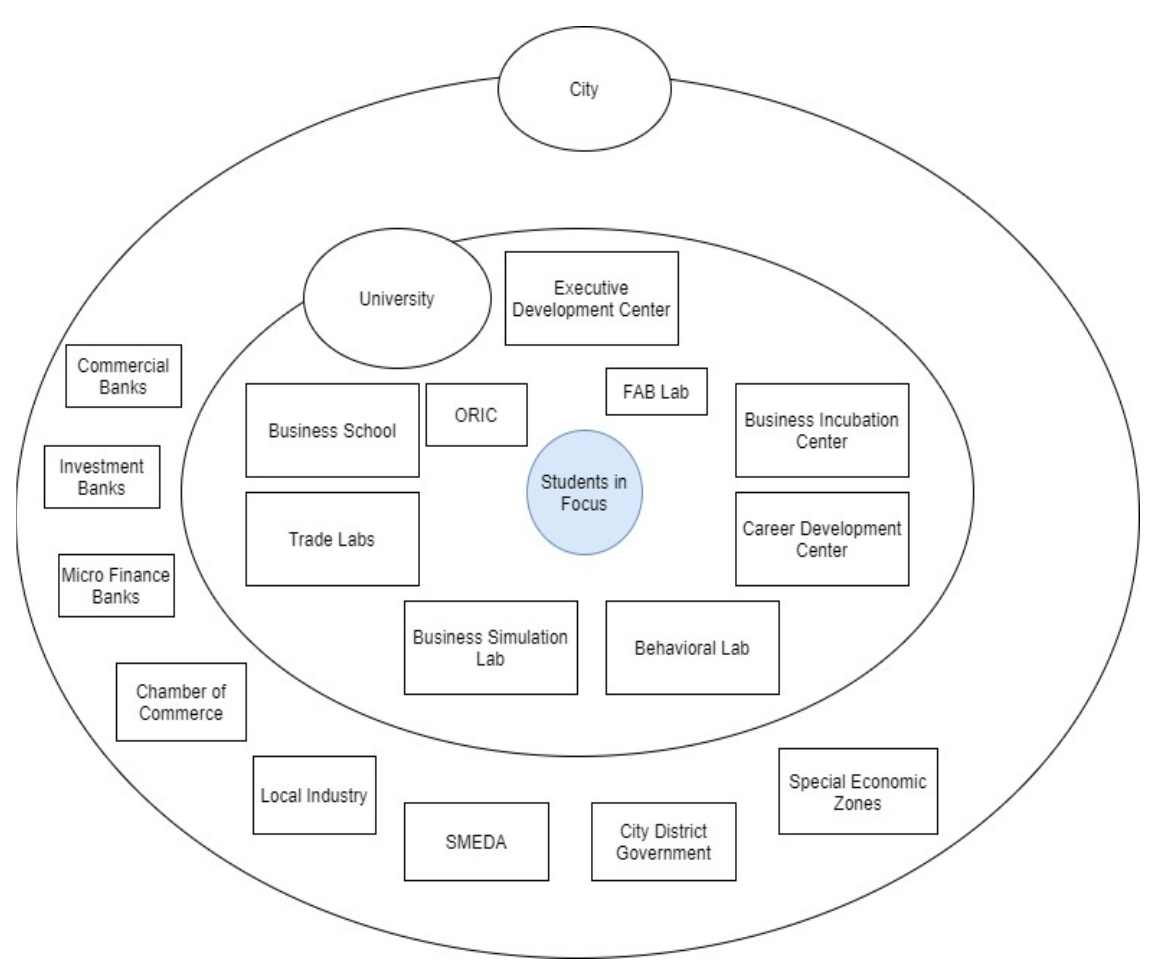

\section{DISCUSSION}

The findings of study 2 reflects study 1, insofar as both suggest that environmental factors, educational institutes and entrepreneurial ecosystem shape students' intentions to become an entrepreneur. Particularly, the findings of study 1 reveals that although the curriculum of Pakistani universities is up-to dated but the number of entrepreneurship courses being taught is limited. The findings of study 1 further revealed that the entrepreneurial ecosystem of Pakistani universities is as good as any world class university. In similar way, results of study 2 suggest that environmental factors like family background plays a key role in shaping students' intention to became an entrepreneur. Likewise, study 2 suggest university and university's entrepreneurial ecosystem significantly contributes to individuals' entrepreneurial intentions.

More specifically, the findings of study 2 reveal that family background of parents is key to entrepreneurial intentions. For instance, if father, mother or any of the family member of an individual has been an entrepreneur, it is more likely that the individual will also become an entrepreneur in future. This finding is in line with the findings of (Carr \& Sequeira, 2007; Zhao et al., 2010), who reported that children inherit entrepreneurial intentions from their parents.

Similarly, the findings suggest that educational institute from where individuals attain their tertiary education is also critical in shaping students' entrepreneurial intentions. The environment, teachers, curriculum, colleagues, facilities at the educational institute together constitute the intentions of individual 
to start his/her business venture in upon completion of the degree. This finding reflects the findings of (Klofsten et al., 2019; Fayolle \& Gailly, 2008), who reported the influence of educational institute on entrepreneurial intentions of the students.

Likewise, the findings of study 2 reveal that entrepreneurial ecosystem of universities also positively affect students' intention to become an entrepreneur. It can be linked to the fact that physical infrastructure of university (i.e. business incubation centers, research labs, trade labs, information technology parks), infrastructure of city in which university is situated (i.e. roads, railway, motorways, and airports) local chamber of commerce, local and federal government policies combinedly shape students' intention to become an entrepreneur. These findings are also in line with previous studies (Miller et al., 2017; Petković et al., 2019) suggested that entrepreneurial ecosystems affect entrepreneurial intentions.

\section{RESEARCH IMPLICATIONS}

This research have some implications and recommendations for policy makers at various government levels. First, the results of study 1 suggest an overall increasing trend of entrepreneurship globally, however, still there is low conversion rate of the intentions into the actual behavior. This highlights the need to create an environment which can help students for nurturing their ideas into startups to capitalize on this trend. To improve the conversion rate of entrepreneurial intentions into actual entrepreneurship, there is a need to start new entrepreneurship courses and degree programs at various educational levels across different academic disciplines in universities which provide practical guide to students for turning their ideas into business venture.

Second, in most of the entrepreneurship courses currently being offered at universities focus on teaching students how to write business programs, therefore there is need to shift focus of entrepreneurship courses from business planning to other activities that may help to shape students' intentions to be entrepreneur. Therefore, universities need to devise their teaching methodologies and curriculum to produce graduates that can recognize and exploit the business opportunities created by fourth industrial revolution. As Petkovic and Kisic (2019) stated that entrepreneurship education at all formal and informal educational levels is regarded as an essential part of entrepreneurial ecosystem, hence by reforming formal and informal educational system to promote entrepreneurial education at various academic levels may results in strengthening entrepreneurial ecosystem.

Third, educational systems that motivate students to be innovative, proactive and to initiate directly affect students' entrepreneurial intentions (Petkovic, 2017; Mustafa et al., 2016). Therefore, there is need to design lectures and class activities at all educational levels in a way that encourage and foster creativity of students in all subjects.

Finally, there is a need to transform the universities into a symbol of entrepreneurship and innovation at the regional and national level in particular business, technology or sector. Universities and public institutions need to work together for developing and promoting an entrepreneurial eco-system in the regional areas of their operation in particular and national in general. There is a need to establish relationship and alliances with the local organization and corporate sector for strengthening the business incubator and services rendered to businesses for further improving favorable entrepreneurial climate. Universities should adopt a competent, innovative and sustainable management for the business incubator which develops the business incubation process according to the local market needs and provides the technical advisory and infrastructure support to students for turning their ideas into business venture. 


\section{REFERENCES}

Audretsch, D.B. (2009). The entrepreneurial society. The Journal of Technology Transfer, 34(3), 245254.

Baumol, W.J. (1990). Entrepreneurship: Productive, Unproductive, and Destructive. Journal of Political Economy, 98(5).

Bischoff, K., Volkmann, C.K., \& Audretsch, D.B. (2018). Stakeholder collaboration in entrepreneurship education: An analysis of the entrepreneurial ecosystems of European higher educational institutions. The Journal of Technology Transfer, 43(1), 20-46.

Bruton, G.D., Ahlstrom, D., \& Si, S. (2015). Entrepreneurship, poverty, and Asia: Moving beyond subsistence entrepreneurship. Asia Pacific Journal of Management, 32(1), 1-22.

Bryman, A., \& Bell, E. (2015). Business Research Methods, 4.

Carr, J.C., \& Sequeira, J.M. (2007). Prior family business exposure as intergenerational influence and entrepreneurial intent: A theory of planned behavior approach. Journal of Business Research, 60(10), 1090-1098.

Cohen, D., \& Crabtree, B. (2006). Qualitative research guidelines project.

Dali, M., Shah, N.R., Abdullah, M., Azman, A.R., Nordin, S.N., Muhammad, I., . . Nilai, B.B. (2014). The relationships between religiosity and entrepreneurial intention. In International Muamalat and Entrepreneurship Conference.

De Carolis, D.M., \& Saparito, P. (2006). Social capital, cognition, and entrepreneurial opportunities: A theoretical framework. Entrepreneurship Theory and Practice, 30(1), 41-56.

Drennan, J., Kennedy, J., \& Renfrow, P. (2005). Impact of childhood experiences on the development of entrepreneurial intentions. The International Journal of Entrepreneurship and Innovation, 6(4), 231-238.

Fayolle, A., \& Gailly, B. (2008). From craft to science. Journal of European Industrial Training.

Fayolle, A., Basso, O., \& Bouchard, V. (2010). Three levels of culture and firms' entrepreneurial orientation: A research agenda. Entrepreneurship and Regional Development, 22(7-8), 707-730.

Galloway, L., \& Brown, W. (2002). Entrepreneurship education at university: A driver in the creation of high growth firms? Education+ Training.

Gelaidan, H.M., \& Abdullateef, A.O. (2017). Entrepreneurial intentions of business students in Malaysia: The role of self-confidence, educational and relation support. Journal of Small Business and Enterprise Development.

Gerring, J. (2004). What is a case study and what is it good for? American Political Science Review, pp. 341-354.

Global Innovation Index. (2019). Retrieved from https://www.wipo.int/edocs/pubdocs/en/wipo_pub_gii_2019.pdf

Gorman, G., Hanlon, D., \& King, W. (1997). Some research perspectives on entrepreneurship education, enterprise education and education for small business management: A ten-year literature review. International Small Business Journal, 15(3), 56-77.

Henderson, R., \& Robertson, M. (2000). Who wants to be an entrepreneur? Young adult attitudes to entrepreneurship as a career. Career Development International, 5(6), 279-287.

Klofsten, M., Fayolle, A., Guerrero, M., Mian, S., Urbano, D., \& Wright, M. (2019). The entrepreneurial university as driver for economic growth and social change-Key strategic challenges. Technological Forecasting and Social Change, 141, 149-158.

Kourilsky, M.L., \& Walstad, W.B. (1998). Entrepreneurship and female youth: Knowledge, attitudes, gender differences, and educational practices. Journal of Business Venturing, 13(1), 77-88.

Krueger, N.F., Jr., Reilly, M.D., \& Carsrud, A.L. (2000). Competing models of entrepreneurial intentions. Journal of Business Venturing, 15(5-6), 411-432.

Laspita, S., Breugst, N., Heblich, S., \& Patzelt, H. (2012). Intergenerational transmission of entrepreneurial intentions. Journal of Business Venturing, 27(4), 414-435. 
Lee, S.H., \& Wong, P.K. (2004). An exploratory study of technopreneurial intentions: A career anchor perspective. Journal of Business Venturing, 19(1), 7-28.

Liñán, F. (2004). Intention-based models of entrepreneurship education. Piccolla Impresa/Small Business, 3(1), 11-35.

Manimala, M.J., Jose, P.D., \& Thomas, K.R. (2006). Organizational constraints on innovation and intrapreneurship: Insights from public sector. Vikalpa, 31(1), 49-50.

Mason, C., \& Brown, R. (2014). Entrepreneurial ecosystems and growth oriented entrepreneurship. Final Report to OECD, Paris, 30(1), 77-102.

Matos, S., \& Hall, J. (2020). An exploratory study of entrepreneurs in impoverished communities: When institutional factors and individual characteristics result in non-productive entrepreneurship. Entrepreneurship \& Regional Development, 32(1-2), 134-155.

Miller, D.J., \& Acs, Z.J. (2017). The campus as entrepreneurial ecosystem: The University of Chicago. Small Business Economics, 49(1), 75-95.

Morris, M., Schindehutte, M., \& Allen, J. (2005). The entrepreneur's business model: Toward a unified perspective. Journal of Business Research, 58(6), 726-735.

Nicolaou, N., \& Shane, S. (2010). Entrepreneurship and occupational choice: Genetic and environmental influences. Journal of Economic Behavior \& Organization, 76(1), 3-14.

Nonaka, I., Byosiere, P., Borucki, C.C., \& Konno, N. (1994). Organizational knowledge creation theory: A first comprehensive test. International Business Review, 3(4), 337-351.

Petković, S., \& Kisić, S. (2019). The necessity of building entrepreneurial ecosystems in the educational system of small post-transition developing economies for the fourth industrial revolution. Journal of Contemporary Economics, 1(1).

Qureshi, S., \& Mian, S. (2020). Transfer of entrepreneurship education best practices from business schools to engineering and technology institutions: Evidence from Pakistan. The Journal of Technology Transfer, pp. 1-27.

Ramakrishna, S., Ngowi, A., Jager, H.D., \& Awuzie, B.O. (2020). Emerging industrial revolution: Symbiosis of Industry 4.0 and circular economy: The role of universities. Science, Technology and Society, 25(3), 505-525.

Sands, R.G., \& Roer-Strier, D. (2006). Using data triangulation of mother and daughter interviews to enhance research about families. Qualitative Social Work, 5(2), 237-260.

Santos, F.J., Roomi, M.A., \& Liñán, F. (2016). About gender differences and the social environment in the development of entrepreneurial intentions. Journal of Small Business Management, 54(1), 4966.

Shapero, A., \& Sokol, L. (1982). The social dimensions of entrepreneurship. University of Illinois at Urbana-Champaign's Academy for Entrepreneurial Leadership Historical Research Reference in Entrepreneurship.

Teng, W., Ma, C., Pahlevansharif, S., \& Turner, J.J. (2019). Graduate readiness for the employment market of the 4th industrial revolution. Education+ Training.

Thornton, P.H., Ribeiro-Soriano, D., \& Urbano, D. (2011). Socio-cultural factors and entrepreneurial activity: An overview. International Small Business Journal, 29(2), 105-118.

Turker, D., \& Selcuk, S.S. (2009). Which factors affect entrepreneurial intention of university students? Journal of European Industrial Training.

Uphoff, N. (2000). Understanding social capital: Learning from the analysis and experience of participation. Social Capital: A Multifaceted Perspective, 6(2), 215-249.

Viswanathan, M., Echambadi, R., Venugopal, S., \& Sridharan, S. (2014). Subsistence entrepreneurship, value creation, and community exchange systems: A social capital explanation. Journal of Macromarketing, 34(2), 213-226.

Zhao, H., Seibert, S.E., \& Lumpkin, G.T. (2010). The relationship of personality to entrepreneurial intentions and performance: A meta-analytic review. Journal of Management, 36(2), 381-404. 